\title{
PENGARUH KEPEMIMPINAN KEPALA SEKOLAH, DISIPLIN KERJA DAN KOMPENSASI TERHADAP KEPUASAN KERJA GURU
}

\author{
Hulmawiyah \\ e-mail: hulma27@gmail.com \\ Lilik Sri Hariani \\ e-mail: liliksrihariani@unikama.ac.id \\ Udik Yudiono \\ e-mail:u_yudiono@unikama.ac.id
}

(Program Studi Pendidikan Ekonomi, Fakultas Ekonomika dan Bisnis, Universitas Kanjuruhan, Malang)

\begin{abstract}
The purpose of this study was to analyze the influence of school principal leadership, work discipline, and compensation to the job satisfaction of teachers of the 10th Vocational High School (SMK) Malang. This research is a type of quantitative research with ex post facto approach. The population in this study were all teachers of State Vocational High School (SMK) 10 Malang, totaling 78 teachers. Sampling uses saturated sample techniques so that all populations are sampled. Data collection techniques using a questionnaire or questionnaire. Data analysis techniques used are descriptive analysis techniques and multiple linear regression analysis with the help of a computer program SPSS 16.00 for Windows. The results of the data analysis showed that the leadership of the school principal, work discipline, and compensation had a positive effect on job satisfaction of teachers of the State Vocational High School (SMK) 10 Malang both simultaneously and partially. Principal leadership, work discipline, and compensation have an effect of $49.3 \%$ on the job satisfaction of teachers of the 10th Vocational High School (SMK) Malang, while 50.7\% is influenced by other variables not examined, such as: work environment, organizational culture work motivation, work stress, etc.
\end{abstract}

Keywords : Job satisfaction, Principal's leadership, Work discipline, Compensation

\begin{abstract}
Abstrak: Tujuan penelitian ini adalah untuk menganalisis pengaruh kepemimpinan kepala sekolah, disiplin kerja, dan kompensasi terhadap kepuasan kerja guru Sekolah Menengah Kejuruan (SMK) Negeri 10 Malang. Penelitian ini merupakan jenis penelitian kuantitatif dengan pendekatan ex post facto. Populasi dalam penelitian ini adalah semua guru Sekolah Menengah Kejuruan (SMK) Negeri 10 Malang yang berjumlah 78 guru. Pengambilan sampel menggunakan tekhnik sampel jenuh sehingga semua populasi dijadikan sampel. Tekhnik pengumpulan data menggunakan angket atau kuesioner. Tekhnik analisis data yang digunakan adalah tekhnik analisis deskriptif dan analisis regresi linier berganda dengan bantuan komputer program SPSS 16.00 for Windows. Hasil analisis data menunjukkan bahwa kepemimpinan kepala sekolah, disiplin kerja, dan kompensasi berpengaruh positif terhadap kepuasan kerja guru Sekolah Menengah Kejuruan (SMK) Negeri 10 Malang baik secara simultan maupun secara parsial. Kepemimpinan kepala sekolah, disiplin kerja, dan kompensasi mempunyai pengaruh sebesar 49,3\% terhadap kepuasan kerja guru Sekolah Menengah Kejuruan (SMK) Negeri 10 Malang, sedangkan 50,7\% dipengaruhi oleh variabel lain yang tidak diteliti, seperti: lingkungan kerja, budaya organisasi, motivasi kerja, stress kerja, dan lain sebagainya.
\end{abstract}

Kata kunci : Kepuasan kerja, Kepemimpinan kepala sekolah, Disiplin kerja, Kompensasi 


\section{PENDAHULUAN}

Pendidikan bagi bangsa merupakan kebutuhan mutlak yang harus dikembangkan sejalan dengan tuntutan pembangunan secara tahap demi tahap. Pendidikan berhubungan dengan proses pengembangan pengetahuan, kecakapan dan keterampilan seseorang (Hardjanto, 2012 : 69). Karena pendidikan merupakan hal yang paling utama dalam pengembangan sumberdaya manusia, maka tenaga pendidik tentunya memiliki tanggung jawab yang sangat besar dalam mengembangkan sumberdaya manusia melalui pendidikan kepada siswa.

Salah satu tujuan pendidikan yang tertuang dalam Undang-Undang No. 20 Tahun 2003 adalah untuk mengembangkan potensi peserta didik. Memperbaiki dan meningkatkan kualitas tenaga pendidik atau guru merupakan salah satu upaya agar tujuan pendidikan tersebut dapat tercapai, karena guru adalah adalah orang pertama yang bertatap muka dengan siswa dalam hal mentransfer ilmu. Guru dituntut untuk membawa anak didiknya dalam rangka mencapai tujuan pendidikan melalui interaksi belajar-mengajar. Oleh sebab itu guru dituntut memiliki kemampuan tinggi dalam melaksanakan tugasnya. Namun, seorang Guru tidak hanya harus dituntut dengan berbagai tugas dan kegiatan yang berat tanpa harus diperhatikan tentang kesejahteraan baik dalam bidang material ataupun inmaterial.

Terpenuhinya segala macam keperluan dan kebutuhan guru secara standar normal tentunya akan memberikan rasa kepuasan tersendiri bagi seorang guru dalam menjalankan tugas dan mengajar. Kepuasan dalam bekerja merupakan aspek penting bagi produktivitas seorang guru, karena apabila seorang guru telah memiliki rasa kepuasan kerja yang baik maka guru akan lebih giat dalam menjalankan tugas-tugasnya dan dapat bekerja lebih profesional, sehingga akan bermuara pada peningkatan mutu pendidikan. Banyak hal yang dapat mempengaruhi kepuasan kerja guru. Salah satu faktor yang dimungkinkan dapat mempengaruhi yaitu kepemimpinan kepala sekolah. Kepala sekolah memegang peranan penting dalam terwujudnya rasa kepuasan kerja yang tinggi bagi seorang guru. Dalam meningkatkan kepuasan kerja guru, kepala sekolah sebagai pemimpin harus memiliki dan menguasai pelaksanaan manjemen sekolah yang baik „, karena kemampuan melaksanakan manajemen yang dimiliki kepala sekolah akan dapat membimbing, mengarahkan bahkan membina guru dalam melaksanakan tugasnya dengan baik dan benar. Tipe kepemimpinan kepala sekolah yang baik akan dapat menjamin kepuasan kerja yang terwujud melalui unjuk kerja para guru dalam melaksanakan tugasnya (Megasari : 2014). Hal ini sejalan dengan penelitian yang dilakukan oleh Sudharto : 2011, bahwa kepemimpinan kepala sekolah berpengaruh positif dan signifikan terhadap kepuasan kerja guru.

Faktor lain yang dimungkinkan dapat mempengaruhi kepuasan kerja adalah disiplin kerja. Seperti penelitian yang telah dilakukan oleh Caryono. : 2010, hasil penelitiannya menyatakan bahwa kedisiplinan dalam bekerja berpengaruh positif terhadap kepuasan kerja guru. Disiplin dalam bekerja di sekolah merupakan suatu usaha sadar dalam mentaati segala peraturan yang berlaku di sekolah. Apabila seorang guru telah dapat menerapkan disiplin kerja yang baik, maka akan menimbulkan kepuasan tersendiri bagi dirinya maupun atasannya, karena merasa bisa menyelesaikan tugas dan kewajibannya secara efektif sebagai seorang guru.

Faktor selanjutnya yang dimungkinkan dapat mempengaruhi kepuasan kerja guru adalah kompensasi. Kompensasi di sekolah merupakan segala sesuatu yang diterima para oleh para guru sebagai balas jasa atas pekerjaan mereka. Pemberian kompensasi haruslah adil dan sesuai dengan tingkat pekerjaan seorang guru, agar ia bisa lebih bersemangat dalam melaksanakan tanggung 
jawabnya. Apabila kompensasi sudah diberikan secara adil dan sesuai dengan tingkat pekerjaannya, maka ia cenderung puas atas hasil dari pekerjaan yang ia tekuni. Hal ini sesuai dengan penelitian yang di lakukan oleh Tanthowi : 2014, bahwa kompensasi dapat mempengaruhi kepuasan kerja guru.

Sekolah Menengah Kejuruan (SMK) Negeri 10 Malang merupakan salah satu sekolah unggulan di kota Malang, di mana lulusannya dapat bersaing dengan lulusan sekolah unggulan di kota Malang. Kepuasan kerja guru sangatlah di butuhkan agar setiap guru dapat melaksanakan tugasnya dengan baik, sehingga akan mengahasilkan lulusan yang baik dan dapat bersaing untuk masuk di Perguruan Tinggi Negeri (PTN). Berdasarkan observasi yang dilakukan oleh peneliti, terdapat sebagian besar guru sudah mendapatkan kepuasan kerja yang baik di sekolah. Hal ini di tandai dengan giatnya setiap guru di Sekolah Menengah Kejuruan Negeri 10 Malang dalam melaksanakan tugas-tugasnya. Peneliti merasa bahwa hal ini layak untuk diteliti, karena rasa ingin tahu peneliti terhadap hal yang mendasari kepuasan kerja guru di Sekolah Menengah Kejuruan Negeri 10 Malang. Tujuan dalam penelitian ini adalah untuk: 1) Menganalisis pengaruh secara simultan kepemimpinan kepala sekolah, disiplin kerja, dan kompensasi terhadap kepuasan kerja guru di Sekolah Menengah Kejuruan (SMK) Negeri 10 Malang, 2) Menganalisis pengaruh secara parsial kepemimpinan kepala sekolah terhadap kepuasan kerja guru di Sekolah Menengah Kejuruan (SMK) Negeri 10 Malang, 3) Menganalisis pengaruh secara parsial disiplin kerja terhadap kepuasan kerja guru di Sekolah Menengah Kejuruan (SMK) Negeri 10 Malang, 4) Menganalisis pengaruh secara parsial kompensasi terhadap kepuasan kerja guru di Sekolah Menengah Kejuruan (SMK) Negeri 10 Malang.

\section{TINJAUAN PUSTAKA}

\section{Kepuasan Kerja}

Wibowo (2013: 132) menyatakan bahwa kepuasan kerja adalah penilaian terhadap karakteristik pekerjaan dan pengalaman emosional di lingkungan pekerjaan yang di rasakan. Kurniawanto: 2016 juga menyatakan bahwa kepuasan kerja merupakan suatu sikap seseorang baik senang dan tidak senang maupun puas dan tidak puas terhadap pekerjaannya. Berdasarkan beberapa teori yang telah di uraikan, maka dapat disimpulkan bahwa kepuasan kerja adalah sikap atau perasaan seseorang terhadap aspek-aspek yang menyenangkan atau tidak menyenangkan mengenai pekerjaan yang sesuai dengan penilaian masing-masing pekerja.

Ahmadiansyah (2016: 229) membagi aspek dan indikator kepuasan kerja guru kedalam beberapa bagian, diantaranya yaitu: a) Keterlibatan guru, dengan indikator: keterlibatan guru dalam membuat keputusan sekolah, keterlibatan guru dalam penyusunan program sekolah. b) Harapan guru, dengan indikator: keberhasilan mengajar, aktivitas di dalam kelas, dan proses belajar mengajar. c) Hubungan antar personil, dengan indikator: hubungan guru dengan kepala sekolah, hubungan guru dengan guru, dan hubungan guru dengan peserta didik

\section{Kepemimpinan Kepala Sekolah}

Menurut Malia (2017: 32), kepemimpinan kepala sekolah merupakan cara dan usaha kepala sekolah dalam membimbing dan mengarahkan guru, maupun siswa dan pihak terkait untuk bekerja guna mencapai tujuan yang ditetapkan. Sedangkan Noerdin: 2016, juga menyatakan bahwa kepemimpinan kepala sekolah adalah kemampuan kepala sekolah dalam mengelola sekolah berdasarkan keterampilan-keterampilan yang dimiliki sebagai syarat mutlak yang harus dimiliki seorang pemimpin pendidikan. Sujak dalam Ruhaediyati :2014, juga menyatakan bahwa 
kepemimpinan kepala sekolah adalah suatu kegiatan dalam usaha untuk memengaruhi, mendorong, membimbing, mengarahkan dan menggerakkan guru dengan melakukan pendekatan sesuai situasi tertentu dan tingkat kematangan (kedewasaan) para bawahan atau staf yang dipimpinnya.

Murni : 2010, membagi faktor-faktor dan indikator kepemimpinan kepala sekolah menjadi beberapa bagian, di antaranya yaitu :

Conseptual skill

Conceptual skills yaitu kemampuan analisis berpikir rasional, mampu menganalisis berbagai kejadian, mampu memahami berbagai kecenderungan, ahli atau cakap dalam berbagai konsepsi, mampu megenali macam-macam kesempatan dan problema sosial. Dalam conseptual skill ini kepala sekolah di tuntut untuk bisa merencanakan semua kegiatan sekolah dengan baik, mampu mendiagnosa permasalahan di sekolah, dan mengkoordinasi kegiatan sekolah.

Human Skill

Human skill merupakan kemampuan untuk memahami sikap orang lain, memahami proses kerja sama, kemampuan berkomunikasi secara jelas dan efektif. Dalam human skill ini kepala sekolah di tuntut untuk dapat menjalin kerjasama dan komunikasi yang baik dengaan bawahannya, mengikutsertakan guru dalam merumuskan pengambilan keputusan, dan dapat memberikan penghargaan kepada guru yang berprestasi.

Technical skill

Technical skill yaitu kemampuan untuk memanfaatkan serta mendayagunakan sarana, menguasai pengetahuan tentang metode, prosedur dan teknik untuk melaksanakan kegiatan khusus. Dalam technical skill ini kepala sekolah di tuntut untuk dapat membimbing guru dalam melaksanakan proses belajar mengajar dengan tujuan agar apa yang di harapkan sekolah dapat tercapai, dan mengkoordinasi dengan baik penggunaan peralatan pengajaran.

\section{Disiplin Kerja}

Afandi (2016: 1) menyatakan bahwa disiplin kerja adalah suatu tata tertib atau peraturan yang di buat oleh manajemen suatu organisasi, dimana orang-orang yang tergabung dalam organisasi tunduk pada tata tertib yang ada dengan rasa senang hati. Disiplin kerja merupakan kesediaan seseorang dalam mentaati semua peraturan norma-norma sosial yang berlaku (Hasibuan, 2010:212).

Indikator disiplin kerja menurut Afandi (2016: 10), meliputi 2 dimensi, yaitu: a) Dimensi ketaatan waktu, dengan indikator : Masuk kerja tepat waktu, penggunaan waktu secara efektif, dan tidak pernah mangkir atau tidak kerja. b) Dimensi tanggung jawab, dengan indikator : Mematuhi semua peraturan organisasi, target pekerjaan, dan membuat laporan kerja harian.

\section{Kompensasi}

Handoko (2014: 155) menyatakan bahwa kompensasi adalah segala sesuatu yang di terima seseorang sebagai balas jasa untuk kerja mereka. Rachmawati (2008: 144), juga menyatakan bahwa kompensasi adalah keseluruhan balas jasa yang di terima oleh seseorang sebagai balas jasa dari pekerjaan di organisasi. Hasibuan dalam Ruhaediyati: 2014 juga menyatakan bahwa kompensasi itu segala sesuatu yang dianggap sebagai suatu balas jasa atau ekuivalen. Menurut Nitisemito dalam Suryadharma (2016: 340), kompensasi merupakan balas jasa yang diberikan perusahaan kepada perusahaannya yang dapat dinilai dengan uang dan mempunyai kecenderungan diberikan secara tetap. 
Menurut Simamora (2008: 445) kompensasi terbagi menjadi 2 bagian, yaitu: a) Kompensasi langsung (direct compensation) yang terdiri dari: gaji, bonus, dan komisi. b) Kompensasi tidak langsung (indirect compensation) yang terdiri dari: program perlindungan (asuransi kesehatan, asuransi jiwa, pensiun, dan asuransi tenaga kerja), fasilitas (kendaraan, ruang kantor, dan tempat parkir).

Kajian empiris yang digunakan dalam penelitian ini adalah: a) Penelitian Sudharto: 2011, tentang pengaruh kepemimpinan kepala sekolah dan kompensasi terhadap kepuasan kerja Guru SMPN Kota Semarang. b) Penelitian Caryono: 2010, tentang pengaruh disiplin kerja, motivasi, budaya organisasi, dan stress kerja terhadap kepuasan kerja Guru pada SLTA dibawah Yayasan Muhammadiyah Sekabupaten Purworejo. c) Penelitian Tanthowi: 2014, tentang pengaruh kompensasi terhadap kepuasan kerja Guru tetap definitif SD Islam Al-azhar Bintaro. d) Penelitian Ruhaediyati: 2014, dengan judul Pengaruh kepemimpinan kepala sekolah dan pemberian kompensasi terhadap kepuasan kerja Guru SMP Negeri Sekecamatan Rangkasbitung Kabupaten Lebak. e) Penelitian Saleem: 2015, yang berjudul the impact of leadership styles on job satisfaction and mediating role of perceived organizational politics. f) Penelitian Salisu: 2015, yang berjudul the impact of compensation on the job satisfaction of public sector construction works of Jigawa state of Nigeria.

Kepemimpinan kepala sekolah, disiplin kerja, dan kompensasi merupakan tiga komponen penting dalam sebuah organisasi. Ketiga hal tersebut dapat mempengaruhi tingkat kepuasan kerja seseorang dalam melakukan pekerjaan yang dibebankan kepadanya. Wibowo (2013: 132) menyatakan bahwa kepuasan kerja adalah penilaian terhadap karakteristik pekerjaan dan pengalaman emosional di lingkungan pekerjaan yang di rasakan. Menurut Uno : 2008 kepuasan kerja dapat di pengaruhi oleh beberapa factor, salah satunya yaitu kepemimpinan kepala sekolah. Kepemimpinan kepala sekolah adalah kemampuan kepala sekolah dalam mengelola sekolah berdasarkan keterampilanketerampilan yang dimiliki sebagai syarat mutlak yang harus dimiliki seorang pemimpin pendidikan (Noerdin : 2016). Dalam meningkatkan kepuasan kerja guru, kepala sekolah sebagai pemimpin harus memiliki dan menguasai pelaksanaan manjemen sekolah yang baik,, karena kemampuan melaksanakan manajemen yang dimiliki kepala sekolah akan dapat membimbing, mengarahkan bahkan membina guru dalam melaksanakan tugasnya dengan baik dan benar. Tipe kepemimpinan kepala sekolah yang baik akan dapat menjamin kepuasan kerja yang terwujud melalui unjuk kerja para guru dalam melaksanakan tugasnya (Megasari : 2014).

Selain itu, Mullin yang dikutip oleh Wijono: 2010 menyatakan bahwa kepuasan kerja juga dapat dipengaruhi oleh disipilin kerja. Menurut Marwanto \& Riyadi (2014: 77), Disiplin kerja tingkah laku dalam mentaati peraturan-peraturan yang berlaku di setiap pekerjaan. Berbagai aturan atau norma yang ditetapkan oleh suatu organisasi atau sekolah memiliki peran yang sangat penting dalam menciptakan kedisiplinan agar para guru maupun karyawannya dapat mematuhi dan melaksanakan peraturan tersebut. Aturan-aturan atau norma yang berlaku pada setiap sekolah biasanya di ikuti sanksi yang di berikan bila terjadi pelanggaran. Sanksi tersebut bisa berupa teguran, baik lisan maupun tulisan, skorsing, bahkan sampai pemecatan kerja tergantung dari besarnya pelanggaran yang dilakukan oleh guru, hal itu dimaksudkan agar guru dapat bekerja dengan disiplin dan bertanggung jawab atas pekerjaannya. Pada dasarnya setiap guru dituntut untuk memiliki sikap disiplin yang tinggi, agar dapat menyelesaikan tugas dan kewajibannya secara efektif sehingga timbul kepuasan kerja bagi dirinya maupun atasannya. 
Hasibuan dalam Tanthowi (2014: 72) mengatakan bahwa selain kepemimpinan kepala sekolah dan disiplin kerja, kepuasan kerja juga dapat dipengaruhi oleh balas jasa atau kompensasi. Menurut Handoko (2014: 155) menyatakan bahwa kompensasi adalah segala bentuk sesuatu yang di terima seseorang sebagai balas jasa untuk kerja mereka. Pemberian kompensasi haruslah adil dan sesuai dengan tingkat pekerjaan seorang guru atau karyawan, agar seorang guru bisa lebih bersemangat dalam melaksanakan tugasnya sehingga ia bisa melaksanakan tanggung jawabnya secara efektif. Apabila kompensasi sudah diberikan secara adil dan sesuai dengan tingkat pekerjaannya, maka ia cenderung puas atas hasil dari pekerjaan yang ia tekuni. Seseorang yang merasa puas dengan imbalan yang diterima atas pekerjaannya akan tercermin dalam sikap positifnya terhadap pekerjaan dan segala sesuatu yang dihadapi ataupun ditugaskan dilingkungan kerjanya.

\section{METODE}

Penelitian ini merupakan penelitian kuantitatif dengan pendekatan ex-post facto. Penelitian ini menggali fakta-fakta yang peristiwanya telah terjadi dengan meggunakan angket yang berisi sejumlah pernyataan yang merefleksikan persepsi responden terhadap kepuasan kerja, kepemimpinan kepala sekolah, disipilin kerja, dan kompensasi. Populasi dalam penelitian ini adalah semua guru di Sekolah Menegah Kejuruan (SMK) Negeri 10 Malang yang berjumlah 78 orang. Pengambilan sampel menggunakan tekhnik sampel jenuh, sehingga semua populasi dijadikan sampel. Tekhnik analisis data menggunakan analisis regresi linier berganda dan pengujian hipotesis menggunakan analisis uji $\mathrm{F}$ dan uji t.

\section{HASIL DAN PEMBAHASAN}

Berdasarkan hasil penelitian yang dilakukan, diperoleh data responden sebanyak 78 orang diberikan angket yan berisi 16 pernyataan variabel kepuasan kerja, 16 pernyataan variabel kepemimpinan kepala sekolah, 12 pernyataan variabel disiplin kerja, dan 8 pernyataan variabel kompensasi. Data yang diperoleh kemudian diolah menggunakan perhitungan dengan bantuan SPSS versi 16.00 for windows. Pengelolaan data menggunakan statistik dan model regresi linier berganda. Hasil analisis regresi linier berganda dapat dilihat pada Tabel. 1 dibawah ini:

Tabel. 1

Hasil Analisis Regresi Linier Berganda

Coefficients ${ }^{\mathrm{s}}$

\begin{tabular}{|c|c|c|c|c|c|c|}
\hline \multirow{2}{*}{\multicolumn{2}{|c|}{ Madel }} & \multicolumn{2}{|c|}{ Unstandardized Coefficients } & \multirow{2}{*}{$\begin{array}{c}\begin{array}{c}\text { Standardized } \\
\text { Coefficients }\end{array} \\
\text { Beta }\end{array}$} & \multirow[b]{2}{*}{$t$} & \multirow[b]{2}{*}{ Siq. } \\
\hline & & $\mathrm{B}$ & Std. Error & & & \\
\hline \multirow[t]{4}{*}{1} & (Constant) & 18.865 & 6.202 & & 3.042 & .003 \\
\hline & $\begin{array}{l}\text { Kepemimpinan_kepala_ } \\
\text { sekolah }\end{array}$ & .216 & .066 & .331 & 3.263 & .002 \\
\hline & Disiplin_kerja & .464 & .110 & .429 & 4.221 & .000 \\
\hline & Kompensasi & .303 & .127 & .197 & 2.378 & .020 \\
\hline
\end{tabular}

a. Dependent Variable: Kepuasan_kerja

Sumber: Hasil olahan SPSS versi 16.00 for windows

Setelah melihat hasil analisis tersebut, maka dapat diketahui variabel bebas (independen) berpengaruh dengan variabel terikat (dependen). Pengaruh variabel bebas dapat dilihat berdasarkan ketepatannya (nilai yang paling siginifikan) dari masing-masing variabel bebas, jadi variabel disiplin kerja (X2) memiliki pengaruh yang yang lebih besar terhadap kepuasan kerja (Y), karena nilai disiplin kerja (X2) koefisien determinasinya lebih besar daripada kepemimpinan kepala sekolah (X1) dan 
kompensasi (X3) yaitu 0,464>0,216 dan 0,464>0,303. Hal ini menunjukkan disiplin kerja merupakan hal yang paling berpengaruh terhadap kepuasan kerja guru Sekolah Menengah Kejuruan (SMK) Negeri 10 Malang.

Menjawab hipotesis yang telah disebutkan, pengaruh secara simultan (secara bersama-sama) dapat digunakan uji F. Hasil uji F dapat dilihat pata Tabel.2 dibawah ini:

Tabel. 2

Hasil Uji F

\begin{tabular}{|l|r|r|r|r|r|}
\hline ANOVA & \\
\hline 1 & Sum of & df & Mean Square & F & Sig. \\
\hline Squares & 5377.736 & 3 & 1792.579 & 23.950 & $.000^{=}$ \\
Regression & 5538.726 & 74 & 74.848 & & \\
Total & 10916.462 & 77 & & & \\
\\
a. Predictors: (Constant), Kompensasi, Kepemimpinan_kepala_sekolah, \\
Disiplin_kerja \\
b. Dependent Variable: Kepuasan_kerja
\end{tabular}

Sumber: Hasil olahan SPSS versi 16.00 for windows

Berdasarkan Tabel. 2 didapat nilai Fhitung sebesar 23,950 dengan tingkat signifikansi 0,000. Karena tingkat signifikan F lebih kecil dari 0,05, berarti kepemimpinan kepala sekolah, disiplin kerja, dan kompensasi secara bersama-sama (simultan) berpengaruh signifikan terhadap kepuasan kerja guru di Sekolah Menengah Kejuruan (SMK) Negeri 10 Malang.

Perlunya rasa kepuasan kerja bagi guru sangatlah penting, karena dengan adanya rasa puas dalam diri seorang guru dapat menjadikannya lebih bersemangat dalam menjalankan tugasnya sehingga keberhasilan sekolah lebih mudah untuk dicapai. Untuk menumbuhkan semangat yang tinggi diperlukan adanya kepemimpinan yang baik dari kepala sekolah. Adanya kerjasama yang baik dari kepala sekolah membuat guru merasa dirinya dihargai dan tidak merasa canggung dalam mengemukakan pendapat misalkan pada saat membuat perencanaan sekolah. Kepemimpinan kepala sekolah yang baik juga cenderung membuat para guru disiplin dalam bekerja. Guru cenderung senang apabila dapat mendisiplinkan dirinya misalkan: datang tepat waktu disekolah, dapat menggunakan waktu dengan seefisien mungkin, dan juga guru sangat senang apabila dapat melaksanakan tugas dan tanggung jawabnya dengan baik. Untuk memudahkan guru dalam melaksanakan tugasnya, guru juga memerlukan adanya fasiitas yang memadai disekolah. Fasilitas yang memadai membuat guru merasa nyaman dan puas bekerja disekolah. Rasa puas itu juga timbul karena adanya gaji pokok maupun pendapatan tambahan diluar gaji pokok misalkan mendapat insentif atau tunjangan yang memadai disekolah.

Melihat pengaruh secara parsial atau pengaruh masing-masing variabel bebas terhadap variabel terikat digunakan uji t. Hasil uji t pada penelitian ini dapat dilihat pada Tabel. 3 dibawah ini:

Tabel. 3

Hasil Uji t

\begin{tabular}{|c|c|c|c|c|c|c|}
\hline \multirow{2}{*}{\multicolumn{2}{|c|}{ Madel }} & \multicolumn{2}{|c|}{ Unstandardized Coefficients } & \multirow{2}{*}{$\begin{array}{c}\begin{array}{c}\text { Standardized } \\
\text { Coefficients }\end{array} \\
\text { Beta } \\
\end{array}$} & \multirow[b]{2}{*}{$\mathrm{t}$} & \multirow[b]{2}{*}{ Siq. } \\
\hline & & $\mathrm{B}$ & Std. Error & & & \\
\hline \multirow[t]{4}{*}{1} & (Constant) & 18.865 & 6.202 & & 3.042 & .003 \\
\hline & $\begin{array}{l}\text { Kepemimpinan_kepala_ } \\
\text { sekolah }\end{array}$ & .216 & .066 & .331 & 3.263 & .002 \\
\hline & Disiplin_kerja & .464 & .110 & .429 & 4.221 & .000 \\
\hline & Kompensasi & .303 & .127 & 197 & 2.378 & .020 \\
\hline
\end{tabular}

a. Dependent Variable: Kepuasan_kerja 
Berdasarkan Tabel. 3 diperolah nilai signifikasi variabel kepemimpinan kepala sekolah sebesar 0,002 lebih kecil dari 0,05, artinya kepemimpinan kepala sekolah memiliki pengaruh yang signifikan terhadap kepuasan kerja guru di Sekolah Menengah Kejuruan (SMK) Negeri 10 Malang. Nilai signifikansi variabel disiplin kerja sebesar 0,000 lebih kecil dari 0,05, artinya disiplin kerja memiliki pengaruh yang signifikan terhadap kepuasan kerja guru di Sekolah Menengah Kejuruan (SMK) Negeri 10 Malang. Nilai signifikansi variabel kompensasi sebesar 0,020 lebih kecil dari 0,05, artinya disiplin kerja memiliki pengaruh yang signifikan terhadap kepuasan kerja guru di Sekolah Menengah Kejuruan (SMK) Negeri 10 Malang.

Berdasarkan hasil penelitian ini, menunjukkan bahwa guru Sekolah Menengah Kejuruan (SMK) Negeri 10 Malang lebih bersemangat dalam bekerja apabila kepemimpinan kepala sekolah di terapkan dengan baik. Adanya koordinasi yang tepat dari kepala sekolah meudahkan para guru dalam melkasnakan tugasnya dan dapat menggunakan alat-alat sekolah dengan tepat pula. Guru juga membutuhkan bimbingan dari kepala sekolah agar proses belajar mengajar dapat terlaksana dengan optimal. Guru merasakan adanya rasa puas dalam pekerjaanya karena adanya kerjasama yang baik dari kepala sekolah.

Rasa puas itu juga timbul karena kedisiplinannya dalam bekerja. Ketika guru dapat menggunakan waktunya dengan baik disekolah. ia merasa senang karena merasa salah satu tugasnya dapat terlaksana. Ketepatan waktunya ketika datang disekolah menjadi contoh bagi siswa, dan ketika ketepatan waktu itu dapat ditiru oleh siswa menjadikan guru merasa puas karena merasa berhasil melaksanan salah satu tanggung jawabnya sebagai seorang guru.

Kepuasan kerja pada guru juga timbul apabila kompensasi yang diterima sesuai dengan harapannya. Kompensasi yang layak akan mendorong semangat guru dalam bekerja. Kompensasi seperti gaji yang diterapkan diinstansi ini sesuai dengan harapan guru, sehingga guru yang bekerja diinstansi merasa puas dengan pekerjaannya. Selain gaji, guru juga merasa senang karena mendapat insentif sebagai tambahan pendapatan diluar gaji pokok. Fasilitas yang disediakan diinstansi ini juga cukup memadai, sehingga guru merasa nyaman berada disekolah dan dapat lebih mudah dalam melaksanakan tugas dan tanggung jawabnya.

\section{KESIMPULAN}

Berdasarkan hasil analisis dan pembahasan yang telah dipaparkan, dapat ditarik kesimpulan: terdapat pengaruh yang positif dan sifnifikan secara simultan kepemimpinan kepala sekolah, disiplin kerja, dan kompensasi terhadap kepuasan kerja guru Sekolah Menengah Kejuruan (SMK) Negeri 10 Malang; terdapat penagaruh yang positif dan signifikan secara parsial kepemimpinan kepala sekolah terhadap kepuasan kerja guru Sekolah Menengah Kejuruan (SMK) Negeri 10 malang; terdapat pengaruh yang positif dan signifikan secara oarsial disiplin kerja terhadap kepuasan kerja guru Sekolah menengah Kejuruan (SMK) negeri 10 Malang; terdapat pengaruh yang positif dan siginifikan secara parsial kompensasi terhadap kepuasan kerja guru Sekolah Menengah Kejuruan (SMK) Negeri 10 Malang .

\section{DAFTAR PUSTAKA}

Afandi, Pandi. 2016. Concept \& Indicator Human Resources Management For Management Research. Yogyakarta: Deepublish 
Ahmadiansyah, Reza. 2016. Pengaruh Motivasi Kerja Dan Kepuasan Kerja Terhadap Kinerja Guru SMK Muhammadiyah Saltiga. Inject, Interdisciplinary Journal Of Communication, Vol. 01. No. 02. Jawa Tengah: UKSW

Caryono, Suhas. 2010. Pengaruh Disiplin Kerja, Motivasi, Budaya Organisasi, Dan Stress Kerja Terhadap Kepuasan Kerja Guru Pada SLTA Dibawah Yayasan Muhammadiyah Sekabupaten Purworejo. JBTI, Vol. 01. No. 01. Hal. 44-62

Darmawan, Didit. 2013. Prinsip-Prinsip Perilaku Organisasi. Surabaya: JP Books

Gulo, Pontinus. 2017. Pengaruh Lingkungan Kerja, Kompensasi, Dan Kepemimpinan Kepala Sekolah Terhadap Kepuasan Kerja Guru Di Sekolah Menengah Atas Se-Sleman Timur. Yogyakarta: Universitas Sanata Dharma

Handoko, T. Hani. 2014. Manajemen Personalia \& Sumber Daya Manusia (Edisi Ke-2, Cetakan Ke-21). Yogyakarta: BPFE

Hardjanto, Imam. 2012. Manajemen Sumber Daya Aparatur (MSDA). Malang

Hasibuan. 2010. Manajemen Sumber Daya Manusia. Jakarta: Bumi Aksara

Kurniasari, Novira. 2014. Hubungan Disiplin Kerja, Lingkungan Kerja, Kompensasi Terhadap Kepuasan Kerja Dan Kinerja Pada Pegawai Politekhnik Kesehatan. Jurnal Ekonomi Manajemen Sumber Daya, Vol. 15. No. 02. Hal. 21-31

Kurniawanto, Hadi. 2016. Pengaruh Kompensasi Dan Motivasi Kerja Terhadap Kepuasan Kerja Pegawai Pada Biro Perlengkapan Dan Asset Sekretariat Daerah Provinsi Banten. JBBE, Vol. 09. No. 02. ISSN: 2087-040 X

Kusumaningtyas, Intan. 2012. Pengaruh Kompensasi Terhadap Kepuasan Kerja Karyawan Bank Mega Dengan Motivasi Kerja Sebagai Variabel Moderasi. Jurnal Manajemen SDM, Vol. 06. No. 02. Desember, Hal. 95-105

Malia, Ikri. 2017. Hubungan Kepemimpinan Kepala Sekolah Dengan Kepuasan Kerja Guru Di Smpn 16 Medan. Sumatera Utara: UIN Sumatera Utara

Marwanto, T. Budi dan Riyadi, N. 2014. Pengaruh Kompensasi Dan Lingkungan Kerja Terhadap Motivasi Dan Disiplin Kerja Prajurit Di Satuan Kerja KRI X Armada RI Kawasan Timur. Jurnal Ilmu Ekonomi \& Manajemen, Vol. 01. No. 01. Hal. 74-82

Megasari. 2014. Pengaruh Tipe Kepemimpinan Kepala Sekolah Terhadap Kepuasan Kerja Guru Sekolah Dasar Negeri Di Kecamatan Ngawen Kabupaten Gunung Kidul. Jurnal Student, Vol. III. No. 5. Yogyakarta : UNY.

Murni, Sri. 2010. Pengaruh Kepemimpinan Kepala Sekolah Dan Motivasi Kerja Guru Terhadap Kinerja Guru SD Negeri Di Kecamatan Dukuhwaru Kabupaten Tegal. Semarang: UNNES

Noerdin, M. Arif. 2016. Pengaruh Kepemimpinan Kepala Sekolah Dan Kinerja Mengajar Guru Terhadap Produktivitas Sekolah Pada Sekolah Dasar Negeri Di Kabupaten Bandung Barat. Bandung: UPI

Rachmawati, I. Kusdyah. 2008. Manajemen Sumber Daya Manusia. Yogyakarta: ANDI

Rivai, Veitzal. 2010. Manajemen Sumberdaya Manusia Untuk Perusahaan. Jakarta: PT. Raja Grafindo Persada

Ruhaediyati, Neneng J. 2014. Pengaruh Kepemimpinan Kepala Sekolah Dan Oemeberian Kompensasi Terhadap Kepuasan Kerja Guru SMP Negeri Sekecamatan Rangkasbitung Kabupaten Lebak. Jurnal Reformasi Administrasi, Vol. 01. No. 01.

Saleem, Hina. 2015. The Impact Of Leadership Styles On Job Satisfaction And Mediating Role Of Perceived Organizational Politics. Pakistan: University Of The Punjab

Salisu, Jamilu B. 2015. The Impact Of Compensation On The Job Satisfaction Of Public Sector Construction Workers Of Jigawa State Of Nigeria. The Business and Management Review, Volume 6 Number 4

Simamora, Bilson. 2008. Panduan Riset Perilaku Konsumen (Cetakan Ke-3). Jakarta: PT. Gramedia Pustaka Utama 
Sudharto. 2011. Pengaruh Kepemimpinan Kepala Sekolah Dan Kompensasi Terhadap Kepuasan Kerja Guru SMPN Kota Semarang. Cakrawala Pendidikan, Th. XXX, No. 03. Semarang: IKIP PGRI Semarang

Suryadharma, I Made Adi. 2016. Pengaruh Kepemimpinan Dan Kompensasi Terhadap Kepuasan Kerja Dan Kinerja Karyawan. E-Jurnal Ekonomi \& Bisnis, ISSN: 2337-3067. Bali: Universitas Udayana

Tanthowi, Imam. 2014. Pengaruh Kompensasi Terhadap Kepuasan Kerja Guru Tetap Definitive SD Islam AlAzhar 17 Bintaro. Epigram, Vol. 11. No. 01. Hal. 71-78

Undang-Undang Republik Indonesia. 2003. Tentang Ketenagakerjaan. Jakarta: Kementrian Pendidikan \& Kebudayaan Republik Indonesia

Uno, Hamzah B. 2008. Teori, Motivasi, Dan Pengukurannya: Analisis Di Bidang Pendidikan. Jakarta: Bumi Aksara

Wibowo. 2013. Perilaku Dalam Organisasi. Jakarta: Rajawali Pers.

Wijono, S. 2010. Psikologi Industri Dan Organisasi: Dalam Suatu Bidang Gerak Psikologi Sumber Daya Manusia. Jakarta: Kencana 